\title{
A Comparative Study of the Mutual Fund Schemes of Reliance and Unit Trust of India
}

\author{
Tom Jacob* and Thomas Paul Kattookaran**
}

\begin{abstract}
The mutual fund industry has experienced phenomenal growth in the past two decades. The increase in the number of schemes with increased mobilisation of funds in the past few years shows the importance of the Indian mutual funds industry. Proper assessment of various fund performance and their comparison with other funds helps retail investors for making investment decisions. Among various financial products, mutual fund ensures the minimum risks and maximum returns to the investors. The development of various mutual funds products has proven to be one of the most catalytic instruments in generating momentous investment growth in the Indian capital market. In this context, close monitoring and evaluation of mutual funds have become essential. Therefore, choosing profitable mutual funds for investment is a very important issue. The main objectives of this research work are to analyse the financial performance of select mutual fund schemes of reliance and UTI through the statistical parameters such as alpha, beta, standard deviation, r-squared, Sharpe ratio. The findings of this research study will be helpful to investors for their future investment decisions.
\end{abstract}

Keywords: Mutual Fund, NAV, Beta, Sharpe Ratio, Standard Deviation.

\subsection{Introduction}

Mutual Funds have become increasingly popular over the last 20 years. They are a type of professionally managed collective investment vehicle. According to SEBI (Mutual Funds) (Amendment) Regulation, 2008, "Mutual fund means a fund established in the form of a trust to raise monies through the sale of units to public or a section of the public under one or more schemes for investing in securities including money market instruments or gold or gold related investments or real assets".

* Assistant Professor, Department of Commerce, Christ College, Kerala.

**Associate professor and Head, Research Department of Commerce, St. Thomas College, Autonomous, Kerala. 
A mutual fund has also been defined as a collection of stocks and/or bonds (Sathya Swaroop, 2008). In other words a mutual fund is a company that brings together money from many people and investors to invest them in stocks, bonds or other assets. Each investor owns shares, which represent a portion of the holdings of the fund. The combined holdings of stocks, bonds, or other assets the fund owns are known as its portfolio. It works on the concept of pooling of money. Savings of the investors are pooled together to invest for their mutual benefit and the returns are distributed proportionately.

Generally Mutual fund companies raise money by selling shares of the fund to the public; much like any other type of company which sell stocks to the public. Mutual Funds take the money they receive from the sale of their shares along with any money made from previous investments and use it to purchase various investment vehicles such as stocks, bonds and money market instruments. In return for the money they give to the fund when purchasing shares, the shareholders receive an equity position in the fund and, in effect, in each of its underlying securities. For most mutual funds, shareholders are free to sell their shares at any time, although the price of a share in a mutual fund will fluctuate daily, depending upon the performance of securities held by the fund.

Mutual fund is most advantageous to small investors (Shanmugham and Zabiulla, 2011). Usually small investors are not able to invest in capital market directly due to lack of expertise in that field. Mutual fund is a great solace for them. It offers the services of experts to make them enjoy the benefits of share market. It provides professional management, diversification, convenience and liquidity. However in India, many people are still not aware of this new investment opportunity.

\subsection{Scope and significance of the study}

Mutual fund is an emerging investment area and there are a lot of mutual fund schemes available for investment in India today. However, investing in mutual fund is a difficult process for common investors (Kundu, 2009). They select those mutual funds that heavily advertise and sell aggressively, without paying attention to their performance. This study aims at measuring the performance of select mutual fund schemes in terms of risk and return so as to help investors to choose the best mutual fund scheme to invest their money. The study covers the 15 select schemes of Reliance Mutual Fund and Unit Trust of India Mutual Fund.

\subsection{Objectives of the study}

The following are the main objectives of the study: 
- To compare various mutual fund schemes of Reliance Mutual Fund and Unit Trust of India Mutual Fund.

- To measure and evaluate the performance of mutual funds schemes in terms of return.

- To know the potential risk involved in each mutual fund scheme.

- To find out the best mutual fund scheme in terms of risk and return

\subsection{Methodology}

This study is based on secondary data. It covers the information related to the selected schemes of Reliance Mutual Fund and Unit Trust of India Mutual Fund. Data is collected from The Handbook of Statistics of Indian Economy, Handbook of SEBI, Indian Securities Market, money.rediff and value research online. The Net Asset Value Returns (Nimalathan and Gandhi, 2009; Debasish, 2009) of various schemes of Reliance Mutual Fund and Unit Trust of India Mutual Fund are analysed. For measuring the risk, various statistical tools like beta (Sondhi and Jain, 2010), standard deviation (Prabakaran and Jayabal, 2010) are used. To know the mutual fund having the highest return at each unit of risk, Sharpe ratio is used.

\subsection{Data Analysis}

\subsection{Average returns}

The average returns of mutual fund schemes of Reliance and UTI are given in Tables $1 \mathrm{a}$ and $1 \mathrm{~b}$ respectively. Table 1a shows the net asset value (NAV) returns of various Mutual Fund Schemes of Reliance Mutual Fund for 5 years along with its average. Reliance Equity Opportunities Fund possesses the highest average NAV Returns. So on the basis of return, Reliance Equity Opportunities Fund is the best one to opt. It gives $33.896 \%$ NAV Returns.

Table 1b shows the NAV Returns of various Mutual Fund Schemes of UTI Mutual Fund for 5 years and their average. UTI Transportation and Logistics Fund has the highest average return of $40.364 \%$ from amongst the selected funds. Therefore, within UTI mutual funds, it is the best scheme in terms of return

\subsection{Beta}

Beta is a measure of volatility of a particular fund in comparison to the market as a whole, that is, the extent to which a fund's return is impacted by market factors. 
74 | MUDRA: Journal of Finance and Accounting, Vol. 2, Issue 1

Table 1a: Average Return of Reliance Mutual Fund Schemes

\begin{tabular}{|c|c|c|c|c|c|c|c|}
\hline \multirow{2}{*}{ No. } & \multirow{2}{*}{ Schemes } & \multicolumn{5}{|c|}{ Annual Return } & \multirow{2}{*}{$\begin{array}{c}\text { Average } \\
\text { Return }\end{array}$} \\
\hline & & 2009 & 2010 & 2011 & 2012 & 2013 & \\
\hline 1 & Reliance Banking Fund & 82.89 & 46.08 & -31.98 & 60.52 & -10.37 & 29.428 \\
\hline 2 & Reliance Equity Fund & 54.72 & 0.28 & -30.11 & 41.28 & 9.25 & 15.084 \\
\hline 3 & $\begin{array}{l}\text { Reliance Equity Opportunities } \\
\text { Fund }\end{array}$ & 108.75 & 30.45 & -21.63 & 47.35 & 4.56 & 33.896 \\
\hline 4 & Reliance Gilt Securities Fund & -9.67 & 3.15 & 4.66 & 13.03 & 3.27 & 2.888 \\
\hline 5 & Reliance Growth Fund & 97.4 & 17.18 & -27.4 & 37.82 & -2.47 & 24.506 \\
\hline 6 & Reliance Income Fund & -0.65 & 4.21 & 6.5 & 11.11 & 2.8 & 4.794 \\
\hline 7 & Reliance Liquid Cash Fund & 2.45 & 4.46 & 8.98 & 9.24 & 8.51 & 6.728 \\
\hline 8 & Reliance LT Equity Fund & 79.29 & 25.98 & -28.61 & 41.66 & 2.88 & 24.24 \\
\hline 9 & Reliance Medium Term Fund & 5.75 & 5.55 & 9.16 & 9.78 & 8.46 & 7.74 \\
\hline 10 & Reliance NRI Equity Fund & 96.81 & 20.76 & -24.49 & 39.28 & 4.62 & 27.396 \\
\hline 11 & $\begin{array}{c}\text { Reliance Quant Plus Fund } \\
\text { Retail } \\
\end{array}$ & 76.55 & 25.4 & -25.16 & 28.52 & 6.08 & 22.278 \\
\hline 12 & $\begin{array}{l}\text { Reliance Regular Savings } \\
\text { Fund (Equity) }\end{array}$ & 102.88 & 19.61 & -29.98 & 46.01 & -3.73 & 26.958 \\
\hline 13 & Reliance Short Term Fund & 8.85 & 5.02 & 7.89 & 9.81 & 7.51 & 7.816 \\
\hline 14 & Reliance Tax Saver Fund & 82.01 & 22.49 & -24.23 & 46.05 & 3.47 & 25.958 \\
\hline 15 & Reliance Vision Fund & 82.13 & 15.26 & -28.55 & 29.98 & -0.31 & 19.702 \\
\hline
\end{tabular}

Table 1b: Average Return of UTI Mutual Funds Schemes

\begin{tabular}{|c|c|c|c|c|c|c|c|}
\hline \multirow{2}{*}{ No } & \multirow{2}{*}{ Schemes } & \multicolumn{5}{|c|}{ Annual Return } & \multirow{2}{*}{$\begin{array}{c}\text { Average } \\
\text { Return }\end{array}$} \\
\hline & & 2009 & 2010 & 2011 & 2012 & 2013 & \\
\hline 1 & UTI Balanced Fund & 62.41 & 16.36 & -19.23 & 27.96 & 6.82 & 18.864 \\
\hline 2 & UTI Banking Sector Fund & 77.75 & 36.48 & -32.58 & 58.69 & -13.51 & 25.366 \\
\hline 3 & UTI Bond Fund & -5.01 & 5.24 & 11.17 & 10.51 & 3.96 & 5.174 \\
\hline 4 & UTI Dividend Yield Fund & 85.78 & 24.27 & -17.54 & 22.37 & 0.2 & 23.016 \\
\hline 5 & UTI Floating Rate Fund ST & 5.95 & 5.42 & 8.23 & 9 & 9.75 & 7.67 \\
\hline 6 & UTI Gilt Advantage Fund & -11.36 & 4.65 & 7.79 & 10.29 & 3.98 & 3.07 \\
\hline 7 & UTI India Lifestyle Fund & 63.16 & 22.98 & -13.93 & 33.14 & 5.83 & 22.236 \\
\hline 8 & UTI Infrastructure Fund & 65.92 & 0.87 & -36.49 & 32.15 & -11.46 & 10.198 \\
\hline 9 & UTI Master Share Fund & 74.16 & 18.47 & -19.72 & 25.07 & 5.9 & 20.776 \\
\hline 10 & UTI Master value Fund & 117.35 & 27.16 & -25.16 & 30.39 & 9.73 & 31.894 \\
\hline 11 & UTI Mid-cap Fund & 110.69 & 18.94 & -23.92 & 41.55 & 9.69 & 31.39 \\
\hline 12 & UTI Mis-Advantage Plan & 21.57 & 7.18 & -0.64 & 15.13 & 6.54 & 9.956 \\
\hline 13 & UTI MNC Fund & 82.03 & 26.17 & -6.04 & 31.26 & 10.63 & 28.81 \\
\hline 14 & UTI Monthly Income Scheme & 17.9 & 7.29 & 2.24 & 11.8 & 6.07 & 9.06 \\
\hline 15 & $\begin{array}{c}\text { UTI Transportation and } \\
\text { Logistics Fund }\end{array}$ & 132.13 & 26.56 & -19.28 & 37.72 & 24.69 & 40.364 \\
\hline
\end{tabular}

Source: www.valueresearchonline.com 
By definition, the market benchmark index of Sensex and Nifty has a beta of 1.0. A beta of 1.0 indicates that the fund NAV will move in same direction as that of benchmark index. The fund will move up and down in tandem with the movement of the markets (as indicated by the benchmark). A beta of less than 1.0 indicates that the fund NAV will be less volatile than the benchmark index. A beta of more than 1.0 indicates that the investment will be more volatile than the benchmark index. It is an aggressive fund that will move up more than the benchmark, but the fall will also be steeper. Scheme having the lowest beta is less risky. Table 2a shows the beta of Reliance Mutual Fund Schemes while Table $2 b$ shows the beta of UTI mutal fund schemes. As is evident from Table $2 a$, the Reliance Liquid cash fund is advisable for investment, as it have the lowest beta of 0.06.It means that even though the market is down, this scheme will be safe; it has the lowest systematic risk.

Table 2a: Beta of Reliance Mutual Fund Schemes

\begin{tabular}{|c|l|l|}
\hline No & \multicolumn{1}{|c|}{ Scheme } & Beta \\
\hline 1 & Reliance Banking Fund & 0.98 \\
\hline 2 & Reliance Equity Fund & 1.07 \\
\hline 3 & Reliance Equity Opportunities Fund & 0.91 \\
\hline 4 & Reliance Gilt Securities Fund & 0.78 \\
\hline 5 & Reliance Growth Fund & 0.98 \\
\hline 6 & Reliance Income Fund & 1.39 \\
\hline 7 & Reliance Liquid Cash Fund & 0.06 \\
\hline 8 & Reliance Long Term Equity Fund & 0.86 \\
\hline 9 & Reliance Medium Term Fund & 0.23 \\
\hline 10 & Reliance NRI Equity Fund & 0.96 \\
\hline 11 & Reliance Quant Plus Fund Retail & 1.06 \\
\hline 12 & Reliance Regular Savings Fund(Equity) & 1.04 \\
\hline 13 & Reliance Short Term Fund & 0.16 \\
\hline 14 & Reliance Tax Saver Fund & 1.01 \\
\hline 15 & Reliance Vision Fund & 1.09 \\
\hline
\end{tabular}

Source: www.valueresearchonline.com 
In the case of mutual funds schemes of UTI, the scheme having least beta is UTI Floating Rate Fund ST (Reg) i.e. 0.08. Therefore that scheme is suitable for investment. It means that even though the market is down, this scheme will be safe. It has the lowest systematic risk.

Table 2b: Beat of UTI Mutual Fund Schemes

\begin{tabular}{|c|l|c|}
\hline No & \multicolumn{1}{|c|}{ Scheme } & Beta \\
\hline 1 & UTI Balanced Fund & 0.92 \\
\hline 2 & UTI Banking Sector Fund(Reg) & 1.03 \\
\hline 3 & UTI Bond Fund & 1.01 \\
\hline 4 & UTI Dividend Yield Fund & 0.81 \\
\hline 5 & UTI Floating Rate Fund ST(Reg) & 0.08 \\
\hline 6 & UTI Gilt Advantage Fund Long Term & 0.65 \\
\hline 7 & UTI India Lifestyle Fund & 0.78 \\
\hline 8 & UTI Infrastructure Fund & 1.2 \\
\hline 9 & UTI Master Share Fund & 0.85 \\
\hline 10 & UTI Master value Fund & 0.95 \\
\hline 11 & UTI Mid-cap Fund & 0.9 \\
\hline 12 & UTI Mis-Advantage Plan & 1.03 \\
\hline 13 & UTI MNC Fund & 0.57 \\
\hline 14 & UTI Monthly Income Scheme & 0.79 \\
\hline 15 & UTI Transportation and Logistics Fund & 1.01 \\
\hline
\end{tabular}

Source: www.valueresearchonline.com

\subsection{Standard deviation}

The total risk (market risk, security-specific risk and portfolio risk) of a mutual fund is measured by 'Standard Deviation' (SD). In mutual funds, the standard deviation tells us how much the return on a fund is deviating from the expected returns based on its historical performance. In other words, can be said it evaluates the volatility of the fund. The standard deviation of a fund measures this risk by measuring the degree to which the fund fluctuates in relation to its average return of a fund over a period of time. In other words, it is a measure of the consistency of a mutual fund's returns. A higher SD number 
indicates that the net asset value (NAV) of the mutual fund is more volatile and, it is riskier than a fund with a lower SD.

Table $3 \mathrm{a}$ and Table $3 \mathrm{~b}$ present the standard deviation of mutual fund schemes of Reliance and UTI. As scheme having the lowest standard deviation is comparatively less risky, so according to table 3a, Reliance Liquid Cash Fund (0.22) should be selected for investment. It means that this scheme is safe both in terms of systematic as well as unsystematic risk. In case of UTI mutual fund schemes, UTI Floating Rate Fund ST (Reg) has the lowest Standard Deviation of 0.43. So this scheme is the best to invest as it is safe both in terms of systematic as well as unsystematic risk.

Table 3a: Standard Deviation of Reliance Mutual Fund Schemes

\begin{tabular}{|c|l|c|}
\hline No & \multicolumn{1}{|c|}{ Scheme } & Standard Deviation \\
\hline 1 & Reliance Banking Fund & 30.12 \\
\hline 2 & Reliance Equity Fund & 20.91 \\
\hline 3 & Reliance Equity Opportunities Fund & 18.69 \\
\hline 4 & Reliance Gilt Securities Fund & 7.16 \\
\hline 5 & Reliance Growth Fund & 20.09 \\
\hline 6 & Reliance Income Fund & 5.62 \\
\hline 7 & Reliance Liquid Cash Fund & 0.22 \\
\hline 8 & Reliance Long Term Equity Fund & 19.61 \\
\hline 9 & Reliance Medium Term Fund & 1.13 \\
\hline 10 & Reliance NRI Equity Fund & 18.79 \\
\hline 11 & Reliance Quant Plus Fund Retail & 20.12 \\
\hline 12 & Reliance Regular Savings Fund(Equity) & 21.09 \\
\hline 13 & Reliance Short Term Fund & 2.17 \\
\hline 14 & Reliance Tax Saver Fund & 21.58 \\
\hline 15 & Reliance Vision Fund & 22.18 \\
\hline
\end{tabular}

Source: www.valueresearchonline.com

\subsection{Sharpe ratio}

Sharpe Ratio is a risk-to-reward measure developed by Nobel Laureate William Sharpe. It is another important measure that evaluates the return that a fund has generated relative to the risk taken. Risk here is measured by SD. It is used for funds that 
have low correlation with benchmark index. This ratio helps an investor to know whether it is a safe bet to invest in this fund by taking the quantum of risk.

Table 3b: Standard Deviation of UTI Mutual Fund Schemes

\begin{tabular}{|c|l|c|}
\hline No & \multicolumn{1}{|c|}{ Scheme } & Standard Deviation \\
\hline 1 & UTI Balanced Fund & 13.63 \\
\hline 2 & UTI Banking Sector Fund(Reg) & 31.72 \\
\hline 3 & UTI Bond Fund & 4.46 \\
\hline 4 & UTI Dividend Yield Fund & 16.05 \\
\hline 5 & UTI Floating Rate Fund ST(Reg) & 0.43 \\
\hline 6 & UTI Gilt Advantage Fund Long Term & 6.11 \\
\hline 7 & UTI India Lifestyle Fund & 15.5 \\
\hline 8 & UTI Infrastructure Fund & 24.6 \\
\hline 9 & UTI Master Share Fund & 16.67 \\
\hline 10 & UTI Mastervalue Fund & 19.58 \\
\hline 11 & UTI Mid-cap Fund & 20.01 \\
\hline 12 & UTI Mis-Advantage Plan & 5.37 \\
\hline 13 & UTI MNC Fund & 14.15 \\
\hline 14 & UTI Monthly Income Scheme & 4.1 \\
\hline 15 & UTI Transportation and Logistics Fund & 22.51 \\
\hline Source: www.valueresearchonline.com & \\
\hline & & \\
\hline
\end{tabular}

The higher the Sharpe ratio (SR), the better a fund's return relative to the amount of risk taken. In other words, a mutual fund with a higher SR is better because it implies that it has generated higher returns for every unit of risk that was taken. On the contrary, a negative Sharpe ratio indicates that a risk-free asset would perform better than the fund being analysed. It tries to find out the excess return generated by a mutual fund over and above a risk-free rate of return such as an RBI bond or a post-office savings scheme, etc.

The calculation for Sharpe Ratio is a risk-adjusted measure, which can be used by an investor to see how well a mutual fund has performed based upon its risk level. An investor can compare similar funds and look for the one with the higher Sharpe Ratio which would indicate the better risk-adjusted Performance. Using the Sharpe Ratio, an 
investor can gain an expectation as to how well the return of a particular mutual fund compensates the investor for the risk taken.

The Sharpe ratio of Reliance Mutual Funds Schemes and of UTI mutual funds schemes are given in tables $4 \mathrm{a}$ and $4 \mathrm{~b}$. As shown in Table $4 \mathrm{a}$, Reliance Liquid Cash Fund has the highest Sharpe Ratio (7.56) .Therefore, in terms of Sharpe ratio, it is the best scheme based on risk and return. This scheme provides the highest return for a given unit of risk taken. An analysis of the Sharpe ratio of various mutual fund schemes of UTI ((Table 4b) shows that the UTI Floating Rate Fund ST (Reg) has the highest Sharpe Ratio i.e. 5.59. Therefore that scheme is the best one on the basis of risk and return. This scheme provides the highest return for a given unit of risk taken.

Table 4a: Sharpe Ratio of Reliance Mutual Fund Schemes

\begin{tabular}{|c|l|c|}
\hline No & \multicolumn{1}{|c|}{ Scheme } & Sharpe Ratio \\
\hline 1 & Reliance Banking Fund & -0.1 \\
\hline 2 & Reliance Equity Fund & -0.09 \\
\hline 3 & Reliance Equity Opportunities Fund & 0.08 \\
\hline 4 & Reliance Gilt Securities Fund & -0.14 \\
\hline 5 & Reliance Growth Fund & -0.27 \\
\hline 6 & Reliance Income Fund & -0.24 \\
\hline 7 & Reliance Liquid Cash Fund & 7.56 \\
\hline 8 & Reliance Long Term Equity Fund & -0.17 \\
\hline 9 & Reliance Medium Term Fund & 1.67 \\
\hline 10 & Reliance NRI Equity Fund & -0.09 \\
\hline 11 & Reliance Quant Plus Fund Retail & -0.19 \\
\hline 12 & Reliance Regular Savings Fund(Equity) & -0.23 \\
\hline 13 & Reliance Short Term Fund & 0.71 \\
\hline 14 & Reliance Tax Saver Fund & 0.01 \\
\hline 15 & Reliance Vision Fund & -0.3 \\
\hline
\end{tabular}

Source: www.valueresearchonline.com

\subsection{Findings}

The study was undertaken to compare the performance of Reliance Mutual Fund and UTI Mutual Fund. The major findings are the following. 
Table 4b: Sharpe Ratio of UTI Mutual Fund Schemes

\begin{tabular}{|c|l|c|}
\hline No & \multicolumn{1}{|c|}{ Scheme } & Sharpe Ratio \\
\hline 1 & UTI Balanced Fund & -0.17 \\
\hline 2 & UTI Banking Sector Fund(Reg) & -0.14 \\
\hline 3 & UTI Bond Fund & -0.11 \\
\hline 4 & UTI Dividend Yield Fund & -0.3 \\
\hline 5 & UTI Floating Rate Fund ST(Reg) & 5.59 \\
\hline 6 & UTI Gilt Advantage Fund Long Term & -0.21 \\
\hline 7 & UTI India Lifestyle Fund & 0.07 \\
\hline 8 & UTI Infrastructure Fund & -0.55 \\
\hline 9 & UTI Master Share Fund & -0.19 \\
\hline 10 & UTI Mastervalue Fund & -0.12 \\
\hline 11 & UTI Mid-cap Fund & 0.05 \\
\hline 12 & UTI Mis-Advantage Plan & 0.05 \\
\hline 13 & UTI MNC Fund & 0.34 \\
\hline 14 & UTI Monthly Income Scheme & 0.01 \\
\hline 15 & UTI Transportation and Logistics Fund & 0.31 \\
\hline
\end{tabular}

Source: www.valueresearchonline.com

- In Reliance Mutual Fund schemes, the scheme showing highest return is Reliance Equity Opportunities Fund (33.896\%)

- In the case of UTI Mutual Fund Schemes, UTI Transportation and Logistics Fund has the highest average return of $(40.364 \%$.)

- On the basis of beta, Reliance Liquid Cash Fund shows the lowest beta (0.06), for Reliance Mutual Fund schemes. So it is the scheme having lowest systematic risk.

- In the case of UTI, Floating Rate Fund ST (Reg) (0.08) shows the lowest beta and hence is the scheme having lowest systematic risk amongst UTI schemes.

- Standard deviation is lowest for Reliance Liquid Cash Fund (0.22) amongst the schemes of Reliance .Therefore it has lowest systematic as well as unsystematic risk.

- Standard deviation is lowest for UTI Floating Rate Fund ST (Reg) (0.43) among the UTI group. Therefore it has lowest systematic as well as unsystematic risk. 
- Among Reliance mutual fund schemes, Sharpe Ratio is the highest for Reliance Liquid Cash Fund (7.56).So it generates the highest return for each unit of risk taken.

- Among UTI schemes, Sharpe Ratio is the highest for UTI Floating Rate Fund ST (Reg) (5.59). So it generates the highest return for each unit of risk taken.

\subsection{Conclusions}

The study was conducted to know the best mutual fund scheme of Reliance Mutual Fund and Unit Trust of India Mutual Fund. From the analysis it is clear that in the case of Reliance Mutual Fund, Reliance Liquid Cash Fund is the best one in terms of risk and return, as it shows the highest Sharpe Ratio, and gives the highest return for a given level of risk. In the case of Unit Trust of India Mutual Funds, UTI Floating Rate Fund ST (Reg) is the best one, as it shows the highest Sharpe Ratio. Thus, these two schemes may be considered by investors for mutual fund investment on the basis of above analysis.

\section{References}

Garg, Sanjay. (2011). A Study on Performance Evaluation of Selected Indian Mutual Funds. International Journal of Innovation Creativity and Management, 1(1): 1-10.

Jayadev, M (1996). Mutual fund performance: An analysis of monthly returns. Finance India, 10(1): 73-84.

Kundu, Abhijit. (2009). Stock selection performance of mutual funds managers in India: An empirical study. Journal of Business and Economic Issues, 1(1): 59-73.

Nimalathan, B. \& Gandhi, R.Kumar. (2009). Mutual fund financial performance analysis: A comparative study on equity diversified schemes and equity mid cap schemes. Excel International Journal of Multi disciplinary Management Studies, 2: 9196.

Prabakaran, G \& Jayabal, G. (2010). Performance evaluation of mutual fund schemes in India: An empirical study. Finance India, 24(4): 1347-1363.

Sathya Swaroop, Debasish. (2009). Investigating performance of equity-based mutual fund schemes in Indian scenario. KCA Journal of Business Management, 2(2): 1-15. 
82 MUDRA: Journal of Finance and Accounting, Vol. 2, Issue 1

Shanmugham, R \& Zabiulla. (2011). Stock selection strategies of equity mutual fund schemes in India. Middle Eastern Finance and Economics, 11: 19-28.

Sondhi, H.J \& Jain, P.K. (2010). Market risk and investment performance of equity mutual funds in India: Some empirical evidence. Finance India, 24(2): 443-464.

\section{Web resources}

www.freepatentsonline.com/article/Asia-Pacific-Business-Review/198667812.html

www.jagoinvestor.com/2012/05/mutual-funds-performance-vs-benchmark.html

www.bseindia.com

www.nseindia.com

www.valueresearchonline.com

www.mutualfundindia.com

www.amfiindia.com

www.bseindia.com

www.sebi.org

www.businessstandard.com

www.rbi.com. 